\title{
A imagem construída sobre a TV Brasil: uma análise do discurso feito pela grande mídia brasileira sobre a televisão pública do país ${ }^{1}$
}

\author{
Iluska Maria da Silva Coutinho², Allana Meirelles Vieira ${ }^{3}$ \\ e Roberta Braga Chaves ${ }^{4}$
}

$\overline{1}$ Trabalho apresentado XVII Congresso de Ciências da Comunicação na Região Sudeste realizado de 28 a 30 de junho de 2012.

2 Doutora em Comunicação Social pela Universidade Metodista de São Paulo (2003), com estágio doutoral na Columbia University (NY). Professora associada do departamento de Jornalismo e do mestrado em Comunicação da Universidade Federal de Juiz de Fora. iluskac@globo.com. Universidade de Aarhus, Dinamarca, com bolsa de estudos da UFJF. Integrante do Grupo de pesquisa "Jornalismo, Imagem e Representação" da UFJF, desde 2010, teve bolsa CNPq. allanameirelles@hotmail.com. 


\section{Resumo}

\section{Palavras-chave}

Este trabalho faz parte do projeto de pesquisa Avaliação do telejornalismo da TV Brasil - monitoramento do cumprimento dos direitos à comunicação e à informação, realizado desde 2010. A pesquisa tem como proposta analisar a televisão pública brasileira, mapeando suas características, refletindo sobre seu papel na sociedade brasileira e propondo caminhos para a efetivação de um sistema mais plural e de caráter público no país. Este artigo em particular analisa a emissora sobre o ponto de vista dos discursos feitos sobre ela na grande mídia, buscando assim, refletir sobre a imagem que se constrói da TV Brasil. Este artigo é realizado a partir de pesquisas bibliográficas que enfocam o tema do sistema público de televisão, assim como através da busca por conteúdos citados pela grande mídia brasileira sobre a TV Brasil.

Telejornalismo, televisão pública, TV Brasil, construção de imagem.

\section{Abstract}

This paper is part of the research project Evaluation of TV Brasil's journalism - monitoring the fulfillment of communication and information rights, realized since 2010. The proposal of the research is to analyze the Brazilian public television, defining their characteristics, thinking about its role in Brazilian society and proposing ways for the achievement of a plural system of communication, based on the public interest. This paper analyzes the channel with the point of view of the speeches made about it in the mainstream media, seeking to discuss the image that is built of TV Brasil. This paper is done from bibliographic researches that focus the public television system, as well as from subjects cited by the Brazilian mainstream media about TV Brasil.

\section{Keywords}

Television journalism, public television, TV Brasil, image building. 
Este artigo faz parte do projeto de pesquisa Avaliação do telejornalismo da TV Brasil - monitoramento do cumprimento dos direitos à comunicação e à informação, em andamento desde 2010. A proposta do projeto é verificar se e de que forma a TV Brasil, a televisão pública brasileira, cumpre este papel público, avaliando diversos aspectos como, por exemplo, sua capacidade técnica, suas escolhas temáticas, assim como propondo mudanças.

A televisão é o meio de comunicação que atinge o maior número de brasileiros. Portanto, estudá-la é importante na busca por um sistema de comunicação que seja mais plural, ético, crítico e justo. Promover a análise da televisão pública brasileira se torna, então, uma tarefa ainda mais justificável, pelo fato de que ela seria a alternativa aos sistemas comerciais e governamentais, capaz de oferecer aos cidadãos uma comunicação de interesse público. Além disso, a TV Brasil é recente no país e, assim, carece de pesquisas que contribuam para sua construção baseada de fato em sua função.

Este estudo pode contribuir tanto para a academia, ao fornecer discussões e pontos de vista acerca de um tema que merece destaque, como para os profissionais envolvidos no processo de produção da TV Brasil em particular e do jornalismo em geral, assim como para o público. A pesquisa como um todo fornece aos profissionais um olhar distanciado e crítico sobre o produto de forma que o produtor possa se tornar consciente de seu trabalho e possa buscar modificações. Dessa forma, o público também é beneficiado ao ter acesso a uma comunicação de qualidade e ao construir um olhar mais questionador diante do que the é oferecido.

A proposta deste artigo, em particular, é apresentar uma análise acerca do discurso feito pela grande mídia sobre a TV Brasil. Através deste recorte, é possível refletir preliminarmente sobre a posição política da mídia em geral e da TV Brasil, assim como pensar sobre o fazer jornalístico no país como um todo. Explicitando a imagem que se constrói da TV Brasil na mídia brasileira, seria possível ainda avaliar como os cidadãos tem acesso ao que seria o papel de emissora. 
Ao longo da pesquisa macro, realizada desde 2010, foi feita a partir de análises quantitativas e qualitativas, nas quais diferentes variáveis foram destacadas. Em um primeiro momento, a separação temática, o tempo das matérias, a caracterização das fontes, a presença do governo e de partidos políticos, assim como o enfoque dado a eles foram os elementos avaliados. Posteriormente, as análises voltaram-se para questões como a edição e o texto do telejornal e das matérias, a programação visual e a inserção das vozes. Para este artigo, a análise se deu a partir de textos sobre a TV Brasil, produzidos pelas revistas: Época, Isto É e pelo blog Observatório da imprensa.

\section{O sistema público de comunicação}

O sistema de radiodifusão brasileiro se baseia na concessão pública, o que confere aos veículos de comunicação uma responsabilidade com o interesse público. De acordo com o artigo 223 da Constituição Nacional de 1988:

Compete ao Poder Executivo outorgar e renovar concessão, permissão e autorização para o serviço de radiodifusão sonora e de sons e imagens, observado o princípio da complementaridade dos sistemas privado, público e estatal (BRASIL, 1988, p.36).

Entretanto, na prática, outros interesses são colocados em prioridade. As emissoras comerciais privilegiam os interesses econômicos, já que se guiam pela lógica do lucro, enquanto as estatais estão ligadas a uma proposta política. A Constituição de 1988, então, estabeleceu uma complementaridade entre os sistemas privado, estatal e público. Porém, foram as emissoras de caráter comercial e as estatais que na realidade estiveram presentes. SODRÉ (2007, p. 9-10) explica que no Brasil, o termo público não tinha lastro de significado, já que era compreendido mais em um sentido estatal.

Em outras palavras, a TV Pública é vista como "o canal do governo", ou seja, algo público, mas que tem dono. Já nos EUA, o tema faz parte da agenda política, sendo possível identificar seus partidários (democratas) e opositores (republicanos). Como parte da verba 
que sustenta o PBS é oriunda do governo federal e aprovada pelo Congresso o investimento em programação não-comercial tem status de política pública (SODRÉ, 2007, p.9-10).

Nessa perspectiva normativa, e de imaginário acerca da televisão pública, em 2007, foi criada a TV Brasil com o intuito de suprir esta lacuna no sistema de radiodifusão brasileiro. As emissoras públicas são consideradas uma alternativa mais plural em relação aos outros padrões, em que o princípio maior seja de fato o interesse público, oferecendo informação de qualidade, isenta e plural, assim como promovendo o diálogo e a representação dos cidadãos. Manoel Pinto discorre sobre a posição da televisão pública em relação a outras.

(...) a lógica televisiva dificilmente se exime a uma teia de interesses e de estratégias que tendem a fazer da TV generalista um poderoso instrumento de conquista. Entendemos que um serviço público de televisão, para que efetivamente o seja, só tem vantagens em se libertar destas amarras e conquistar o seu espaço autônomo, entrosando-se de forma progressiva e consciente com as dinâmicas e as instituições sociais (Pinto, 2003, p. 15).

Presidente da Radiobrás ${ }^{5}$, de 2003 a abril de 2007, Eugênio Bucci defende a existência de uma emissora pública como um direito das pessoas, que sejam autoras, agentes ou espectadoras à informação jornalística, ao conhecimento e às manifestações culturais.

\footnotetext{
As emissoras públicas, em suma, existem para ajudar a sociedade a realizar o ideal da imprensa - que é instituição social, independente do Estado, em que vige a liberdade de expressão, incumbida de fiscalizar o poder. Elas só têm sentido social e histórico se estiverem a serviço da sociedade e dos direitos dos cidadãos (BUCCI, 2010, p. 5).
}

De acordo com PINTO (2001, p.16), "a televisão de serviço público afirmase e diferencia-se pelo seu caráter de referência e de exemplaridade". Assim, ela não nivela por baixo, mas coloca a exigência em um nível mais elevado possível, buscando "o profissionalismo, as especificidades do discurso e estética televisivos, a capacidade de despertar interesse e de alargar horizontes" (Pinto, 2001, p. 16).

A Radiobrás foi uma empresa pública do Governo Federal criada em 1975 para gerir todas as emissoras de TV e rádio do governo federal espalhadas pelo Brasil. Foi incorporada pela Empresa Brasil de Comunicação (EBC) em 2008. 
A emissora pública teria, então, o papel de se diferenciar dos outros sistemas, apresentando conteúdos que não são encontrados em outras emissoras e que se caracterizam por sua pluralidade, ética, independência e valorização do interesse público.

Para Martin-Barbero (2000), a mais clara caracterização de televisão pública é que essa, ao contrário da comercial, interpela mais ao cidadão que ao consumidor. Seu objetivo é contribuir na construção do espaço público enquanto cenário de comunicação e de diálogo entre os diversos atores sociais e as diferentes comunidades culturais (FORT, 2005, p. 100).

Ao refletir sobre a televisão pública, nos remetemos a exemplos de países que adotam esse modelo e que, de certa forma, têm alcançado sucesso. Podemos citar a BBC inglesa, a TVE espanhola, a France Televisón, a RAI italiana, a RTP de Portugal, a $A R D$ e a ZDF alemãs, a PBS dos Estados Unidos, entre outras. Na Europa, a televisão nasceu pública e, portanto, este sistema se encontra consolidado.

No Brasil, por outro lado, a lógica da televisão sempre foi comercial e por isso, se configura uma tarefa complexa a tentativa de mudar e reverter valores e métodos que já estão solidificados no mercado e no imaginário da população. Criar neste contexto uma televisão pública no Brasil é como ter que reensinar as pessoas a assistir televisão e aos poucos, inserir valores que nunca foram questionados, pelo menos não pelo grande público.

Como a TV no Brasil nasceu privada, Bucci afirmou que falar de televisão no Brasil é falar de TV comercial, pois como as televisões abertas são gratuitas, toda formatação da programação televisiva é feita para servir de venda ao anunciante. (...) Em outros países europeus, o modelo é o mesmo (da $\mathrm{BBC}$ ), pois a televisão nasceu pública e recentemente tem migrado à privatização. (...) Portanto, a televisão privada ganha hegemonia e estabelece regras, o que influencia diretamente a proposição de televisão pública (FORT, 2005, p. 88-89).

Sobre a ideia de que todo serviço público deve ter qualidade, esbarramos em outra questão, que não raramente ronda os estudos sobre jornalismo e televisão: como monitorar e medir esta qualidade? Na lógica que considera uma televisão pública uma produção feita também pelo público e não apenas 
para ele, seriam os próprios telespectadores os controladores dessa qualidade. Entretanto, para isso, é necessário educação e olhar crítico, já que o público televisivo não está acostumado a avaliar. Quando alguma crítica é feita, ela se dá pela perspectiva de um consumidor e não de um cidadão.

Tomando a BBC como exemplo, toda residência britânica que tem televisão paga uma taxa anual. A emissora é dirigida por uma diretoria executiva, nomeada por um conselho composto por 12 pessoas representativas da sociedade. Os conselheiros são independentes, ou seja, não têm vínculo com organizações ou instituições comerciais. O modelo de financiamento garante total autonomia à $B B C$. Para o Brasil, pensar em se cobrar uma taxa da população, tendo em vista a grande desigualdade que assola o país, seria algo no mínimo complexo.

A discussão sobre qual seria a melhor forma de transformar a televisão efetivamente em um serviço público genuíno deve levar em conta o país em questão e suas necessidades. Em Televisão e cidadania, Joaquim Fidalgo cita o político José Pacheco Pereira, que diz: "Definir em termos claros o que é o 'serviço público' que o Estado tem obrigação de prestar no domínio da comunicação social e, só depois escolher os meios através dos quais ele é prestado" (MANOEL PINTO, 2003, p. 30). Devemos admitir que esses meios, no Brasil, precisam ser repensados, para depois, implantarmos uma televisão pública de qualidade.

\section{TV Brasil - a emissora pública brasileira}

A TV Brasil foi criada em 2007 com a proposta de suprir uma lacuna no sistema de radiodifusão brasileiro, dominado pelas emissoras de caráter comercial e estatal. Assim, ela seria uma alternativa aos sistemas dominantes, apresentando conteúdos plurais, de interesse público e que dialogasse com a sociedade de forma efetiva. Sua proposta, apresentada em sua carta de apresentação, é de "complementar e ampliar a oferta de conteúdos, oferecendo uma programação de natureza informativa, cultural, artística, científica e formadora da cidadania" (http://tvbrasil.org.br/sobreatv/). 
Gerida pela Empresa Brasil de Comunicação (EBC), a TV Brasil é composta por quatro canais federais. A EBC é responsável por aprovar a programação e os conteúdos, que são supervisionados por um Conselho Curador cuja proposta é representar a sociedade brasileira na fiscalização do cumprimento dos objetivos da empresa. A composição do Conselho envolve 22 membros, 15 indicados pela sociedade, quatro pelo Governo, um pela Câmara, outro pelo Senado além de um representante dos funcionários da emissora.

A emissora é financiada a partir do repasse de verbas do governo federal. Em tese, isso não deveria subordinar a TV Brasil ao papel de porta-voz do governo, mas a estrutura existente em geral é entendida e percebida na sociedade como um risco à liberdade do veículo. Esse é, inclusive, o alerta de seu primeiro presidente, Eugênio Bucci:

Seja no plano político (relações com o governo e o Estado), seja no plano econômico (relações com o mercado), a independência é indispensável para a realização de qualquer projeto de radiodifusão pública (BUCCI, 2010, p. 6).

A concepção de que a emissora pública seria um órgão "chapa branca" perpassa o imaginário social e é potencializada pela cobertura midiática de temáticas relacionadas à emissora e/ou sua programação. Entretanto, os dados obtidos na pesquisa qualitativa indicam a busca por neutralidade e mesmo pluralismo na cobertura de temas polêmicos. Ainda assim, é preciso ressaltar que o principal telejornal da emissora, o Repórter Brasil, apresenta um tom conciliador em temas polêmicos, evitando duras críticas ao governo, sem, porém, necessariamente, defendê-lo.

Esta crítica é potencializada pelo fato de que cabe à empresa EBC a produção de conteúdos para a Secretaria de Comunicação do Governo Federal, o que envolve a produção e geração do programa $A$ voz do Brasil, além das atividades do canal NBR, que em alguns casos atua como produtor/ distribuidor de imagens de eventos realizados no Palácio do Governo. 
Neste contexto, ganham importância as ações do Conselho Curador ao se aproximar das universidades, por meio de pesquisadores, em busca de avaliar a produção da emissora. Por meio de convênios, foram realizados entre 2010 e 2011, projetos de monitoramento da programação infantil e do telejornalismo da emissora, realizados por equipes da Universidade Federal do Ceará e da Universidade Federal de Juiz de Fora, respectivamente.

\section{A imagem que se constrói da TV Brasil}

Nos debates que ganham espaço na esfera pública, especialmente via mídia massiva, com destaque para os espaços de crítica televisiva, a TV Brasil tem sido alvo de críticas e discussões desde sua criação. Em geral, o argumento principal utilizado passa pela desqualificação da emissora e de sua contribuição, em função de sua baixa audiência; propõe-se que o dinheiro do cidadão brasileiro estaria sendo desperdiçado em uma emissora que ninguém assiste.

Mas ao avaliar a televisão pública a partir dos mesmos olhares e parâmetros com que se enxerga as emissoras comerciais acaba-se deixando de lado sua proposta e objetivos diferenciados. Entende-se que uma televisão efetivamente pública deve funcionar em prol do interesse público e não, necessariamente, do interesse do público. Entretanto, esta lógica não exclui a responsabilidade da televisão de produzir conteúdo de qualidade que tenha abrangência nacional, razão pela qual os processos de avaliação e sistematização do conhecimento acerca do telejornalismo público ganham importância.

No dia 21 de outubro de 2011, a revista Época publicou uma reportagem intitulada "A emissora que fala sozinha", com o subtítulo "Prestes a completar quatro anos e com orçamento de R $\$ 450$ milhões, a TV Brasil tem audiência pífia e confunde serviço público com interesses do governo". Antes mesmo de ler a matéria, o leitor já se vê diante de uma conclusão perigosa.

A reportagem apresenta como crítica central a audiência traço da emissora. 
Prestes a completar quatro anos, a TV Brasil continua pouco conhecida, apresenta índices pífios de audiência e seu modelo de organização é criticado por quem atua no setor.Virou, na expressão jocosa dos críticos, a "TV traço", ironia à audiência sempre próxima de zero (Revista Época, 2011).

O fato de não depender da audiência não permite que a emissora pública não busque meios de atingir o público, já que ela só faz sentido se, de fato, comportar-se como meio de representação e diálogo. Entretanto, a TV Brasil não deixa esta preocupação de lado, fato evidenciado, principalmente, pelo contato com a academia, a fim de iniciar um processo de avaliação, não endógeno ressalte-se. A iniciativa partiu do Conselho Curador da emissora, e tem como perspectiva a busca por melhoria a partir da identificação de aspectos falhos.

Assim, em linhas gerais percebe-se que, ainda que a conquista do público tenha que ser uma preocupação intrínseca de qualquer meio de comunicação, desqualificar a emissora a partir deste aspecto, sem ao menos fazer uma análise sobre o produto em si não representa uma crítica construtiva, mas um embate político. Além disso, desconsidera-se, na reportagem, o fato da cultura televisiva brasileira estar atrelada ao sistema comercial, sendo algo estranho à realidade de nossa sociedade uma televisão pública. Finalmente, desconsidera a possibilidade de que o papel dessa emissora pública, talvez, seja atender uma parcela do público que não se vê atendido/ representado com as emissões comerciais.

Outra crítica feita pela reportagem é sobre a lógica de financiamento e de nomeações. De acordo com a matéria, nenhuma emissora pública no mundo tem o controle administrativo escolhido pela autoridade estatal, um sistema de nomeação sem consulta nem aprovação do Senado, como ocorre com as agências reguladoras. Sobre o financiamento vindo do Orçamento da União, a reportagem afirma que caso a linha editorial não agrade ao governo, há a possibilidade de retaliação. Além disso, a matéria cita que "de todas as estranhezas da EBC, a maior é a mistura de atribuições pretensamente públicas às atividades do governo" (Revista Época, 2011). 
Já o Observatório da imprensa publicou no dia 01 de agosto de 2009 um artigo sobre um editorial da Folha de São Paulo, em que este pedia o fim da TV Brasil. O editorial da Folha fazia uma crítica à baixa audiência; à criação por um ato não democrático, já que fora criada por um decreto; e aos gastos anuais com o dinheiro do contribuinte. O texto se encerra da seguinte forma: "Os vícios de origem e o retumbante fracasso de audiência recomendam que a televisão seja fechada - antes que se desperdice mais dinheiro do contribuinte" (Observatório da imprensa, 2009).

Marcelo Salles, autor do artigo do Observatório da imprensa, avalia que existem erros graves na TV Brasil, mas estes não se relacionam com aqueles citados pela Folha e faz críticas severas a este jornal. Para ele, o erro da TV Brasil está na entrega de cargos de direção para jornalistas oriundos das corporações da mídia.

\begin{abstract}
Com isso o governo indicou uma conciliação, não uma mudança substancial no jeito de fazer jornalismo. Assim, não é à toa que muito do conteúdo veiculado pela TV Brasil, sobretudo nos telejornais, tem sido muito parecido com aquele das corporações privadas. Por outro lado, não dá para dizer que é tudo igual. Se pegarmos a programação como um todo, veremos a existência de iniciativas que jamais teriam vez no atual sistema privado de televisão. É o caso dos documentários, que dão voz e vez aos segmentos da sociedade que só aparecem na mídia corporativa como bandidos (Observatório da imprensa, 2009).
\end{abstract}

A revista Isto É também publicou uma matéria questionando o papel público da TV Brasil, em 2008. Em "Pública ou oficial? - Seis meses depois de ir ao ar, TV Brasil tem pouca audiência e é acusada de chapa-branca", o jornalista Rudolfo Lago inicia a matéria dizendo o que se espera de uma emissora pública,

De uma televisão pública, espera-se que expresse o pensamento da sociedade, e não do governo de plantão. Que, sendo de propriedade da sociedade, sua administração seja plural e descentralizada, com a participação dos setores organizados da população. Seis meses depois de criada, a TV Brasil sofre ataques por supostamente não cumprir esses dois pré-requisitos (Isto É, 2008).

A reportagem incluía denúncias de funcionários da emissora de que havia pressão por parte do governo sobre os conteúdos veiculados. "Primeiro, foi o ex- 
editor-chefe da tevê e ex-âncora do Repórter Brasil, telejornal da emissora, Luís Lobo, que saiu denunciando pressão do governo na elaboração do noticiário" (Isto

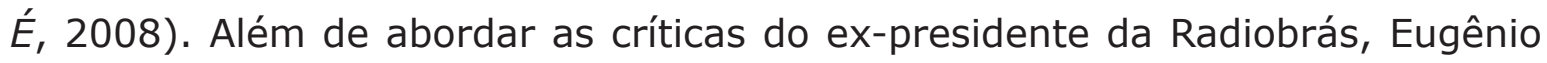
Bucci, sobre os obstáculos criados pelo governo em sua tentativa de criar uma emissora menos governamental e mais pública.

Entretanto, nas análises realizadas durante os meses de agosto a dezembro de 2010, que incluíam o período de eleições presidenciais, verificou-se certa busca pela neutralidade por parte do principal noticiário da TV Brasil, o Repórter Brasil. Os três partidos que apresentavam maior destaque nas pesquisas eleitorais recebiam uma atenção semelhante, já que o tempo de exposição de cada um deles era praticamente o mesmo. Além disso, a maior parte das presenças dos partidos políticos, assim como do próprio governo foram consideradas "neutras" pela análise, ainda que essa imparcialidade seja aparente.

Em diferentes aspectos, a TV Brasil é alvo de críticas e questionamentos. Pouco se apresenta, contudo, acerca da proposta da emissora, dos conteúdos que são oferecidos, ainda que para submeter promessa e produção midiática à crítica.

Refletir sobre o seu trabalho contribui para que a emissora alcance de fato suas propostas com o interesse público e cumpra seus objetivos de pluralidade, independência e representação. Entretanto, é necessário que estas críticas sejam embasadas e tenham como principal foco a construção de um sistema de comunicação de maior qualidade e não a defesa de interesses econômicos e políticos de um grupo.

\section{Considerações finais}

No Brasil, ainda que a televisão seja uma concessão pública, ela nasceu como um empreendimento comercial e não como um serviço público, como na Europa. Assim, nossa cultura midiática está muito mais pautada em uma relação de consumidor e produtor, do que cidadão e representante. Esta lógica acaba influenciando o olhar do público e dos próprios profissionais sobre o conteúdo televisivo que é produzido no país. 
Neste contexto se insere uma emissora que se pretende uma alternativa ao sistema vigente, propondo oferecer informação plural, independente, de interesse público e que seja representativa da diversidade brasileira. A TV Brasil tem o objetivo de preencher lacunas, de colocar em prática a necessidade de uma televisão pública no país. Mas, desde sua criação em 2007, ela tem sido criticada e questionada por setores da sociedade e pela grande mídia. Sua lógica de financiamento e nomeação, sua baixa audiência, seus problemas estruturais geram questionamentos. As críticas vindas de pessoas que fizeram parte da emissora tornam a situação ainda mais complicada.

Refletir sobre o papel da TV Brasil na sociedade brasileira, o cumprimento de seus princípios, suas lógicas estruturais, o conteúdo que é oferecido contribui para que a emissora cresça e encontre uma forma de atingir seus ideais e cumprir sua responsabilidade. Entretanto, é necessário separar o que são críticas e questionamentos que, de fato, buscam um sistema de comunicação mais justo, plural e independente, do que são disputas comerciais e políticas, que atendem apenas a um grupo.

De maneira geral, a imagem construída sobre a TV Brasil é de uma emissora que não cumpre o papel de televisão pública a que se pretende e de que corresponde a uma televisão que ninguém vê. As matérias apresentam o sistema público principalmente pelo enfoque da independência política e econômica que deveria apresentar. Entretanto, a questão da audiência aparece como um destaque em várias reportagens, o que representa um olhar comercial sobre a televisão. Na maior parte das reportagens, implicitamente há uma comparação entre a televisão pública brasileira e as comerciais, fato que obteve oposição clara, porém, do artigo reproduzido pelo Observatório da imprensa.

A TV Brasil possui diversos pontos que devem ser repensados e reestruturados para que o ideal de televisão pública seja atingido. Ainda assim, ela representa um grande passo para a sociedade brasileira, já que no mínimo representa o reconhecimento da necessidade de uma emissora com serviço público no país. 


\section{Referências}

BRASIL. Constituição (1988). Constituição da República Federativa do Brasil. Disponível em: http://www6.senado.gov.br/con1988/CON1988_19.12.2006/ CON1988.pdf. Acesso em: 28 mar. 2013.

BUCCI, E. "É possível fazer televisão pública no Brasil?" Novos estudos, São Paulo, 2010. Disponível em: http://www.scielo.br/scielo.php?pid=S0101$33002010000300001 \&$ script=sci_arttext. Acesso em: 29 jul. 2013.

COUTINHO, I. (coord.). Avaliação do telejornalismo da TV Brasil. Relatório Final. Programa de Pós-Graduação em Comunicação Social, Universidade Federal de Juiz de Fora, Juiz de Fora, 2011.

- Dramaturgia no telejornalismo brasileiro: a estrutura narrativa das notícias em televisão. (Tese de doutorado). Programa de Pós-Graduação em Comunicação Social da Umesp. São Bernardo do Campo, Umesp, 2003.

FORT, M. C. Televisão educativa: a responsabilidade pública e as preferências do espectador. São Paulo: Annablume, 2005.

LAGO, R. "Pública ou oficial? Seis meses depois de ir ao ar, TV Brasil tem pouca audiência e é acusada de chapa-branca". Revista Isto É, edição 2017, 2008. Disponível em: http://www.istoe.com.br/reportagens/11488_PUBLICA+OU+OFICI AL+?pathImagens=\&path=\&actualArea=internalPage. Acesso em: 06 mai. 2013.

MENDONÇA, R. "A emissora que fala sozinha. Prestes a completar quatro anos e com orçamento de $\mathrm{R} \$ 450$ milhões, a TV Brasil tem audiência pífia e confunde serviço público com interesses do governo". Revista Época, 2011. Disponível em: http://revistaepoca.globo.com/tempo/noticia/2011/10/emissora-que-falasozinha.html. Acesso em: 06 mai. 2013. 
PINTO, M. (coord.). Televisão e cidadania: contributos para o debate sobre o serviço público. Porto: Campo das Letras, 2005.

REPÓRTER BRASIL. Disponível em: http://tvbrasil.ebc.com.br/reporterbrasil/ flat/sobre/. Acesso em: 06 jun. 2013.

SALLES, M. "TV Brasil. Folha quer o fim da emissora". Observatório da Imprensa, 2009. Disponível em: http://www.observatoriodaimprensa.com.br/news/view/ folha_quer_o_fim_da_emissora. Acesso em: 06 mai. 2013.

SODRÉ, B. PBS: um modelo de tv pública. Brasília: Casa das Musas, 2007.

TORRES, R. M. M. Televisão pública no Brasil: estudo preliminar sobre suas múltiplas configurações. Rio de Janeiro: Instituto de Comunicação e Informação Científica e Tecnológica em Saúde, Fiocruz, 2009.

TV BRASIL. Disponível em: http://www.tvbrasil.org.br/sobreatv/. Acesso em: 06 jun. 2013. 